\title{
Study of Geometric Elements for the Proposed Protecting Dam Reservoir in Al-Fat'ha Area, Iraq
}

\author{
Sabbar S. Abdallah" ${ }^{1, \mathrm{a}}$, Bahaa Al-Din R. Ali ${ }^{1, \mathrm{~b}}$ and Muhana M. Ahmed ${ }^{1, \mathrm{c}}$ \\ ${ }^{1}$ Department of Applied Geology, Tikrit University, Tikrit, Iraq.

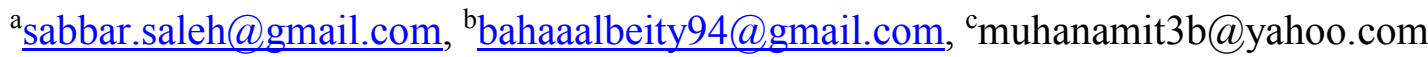

\begin{abstract}
Partially constructed Makhul dam may collapse after the operation due to the geological and geotechnical background of the foundations zone, and the presence of gypsum layers in this zone, Then the construction of Al-Fat'ha protection dam is one of the proposed solutions. The present study used the geometric analysis method to investigate the ability of Al-Fat'ha planned protecting dam to reduce the disasters of Makhul dam break. The new methodology used to derive the geometric elements of the two dams, and analyze the relations between these elements, and then exam the behavior of Al-Fat'ha proposed dam with and without the studied collapse scenarios. Fourteen collapse scenarios suggested for Makhul dam, from the level $140 \mathrm{~m}$ above sea level (a.s.l), to the maximum possible flood level $152 \mathrm{~m}$ (a.s.l). A mathematical model was derived to predict the level achieved as a response of cumulative storage in the protecting dam reservoir when the collapse of the Makhul dam occurred. The maximum level in the protecting dam reservoir to face the worst collapse scenario is $147 \mathrm{~m}$ (a.s.1), when the corresponding accumulated storage in the reservoir is 3414305769 $\mathrm{m}^{3}$. The results of the geometric analysis indicate that the optimum operating level for Al-Fat'ha dam in the operating conditions without Makhul dam collapse is $118.5 \mathrm{~m}$ (a.s.1), which corresponds to the capacity (39243587) $\mathrm{m}^{3}$. The total flooded area between the two dams was calculated for each collapse scenario of Makhul dam; it is about $44 \mathrm{~km}^{2}$ for the worst scenario when nine villages on reservoir banks will submerge. Subsequently, the study confirmed the ability of Al-Fat'ha dam reservoir to contain the direct flood wave caused by the collapse of Makhul dam.
\end{abstract}

Keywords: Geometric elements; Al-Fat'ha dam; Makhul dam; protect dam; dam collapse.

\section{Introduction}

Ministry of water resources in Iraq planned to resumption the construction of the partially constructed Makhoul Dam as one of the main water resources management projects on Tigris River. However, due to engineering, structural, geological, and geotechnical future problems, this dam could be subject to collapse, so, Al-Fat'ha protecting dam was proposed to reduce the flood risks of Makhul Dam possible failure, then, it is necessary to study the geometric elements of Al-Fat'ha proposed protecting dam. Al-Fat'ha dam is located in Al-Fat'ha area north Baiji city, about $17 \mathrm{~km}$ south Makhul dam, and (112) km, north Samarra dam, the suggested reservoir extended from UTM coordinates (367833) to (368948) East and (3879628) to (3879792) North. The total area of the reservoir is about $578 \mathrm{~km}^{2}$, as in the location map, Figure 1. Geologically, Fat'ha formation appears in wide exposures consisting of alternating cycles of marl, limestone, and gypsum. It has about $268 \mathrm{~m}$ thick near AlFat'ha area [1]. This formation is divided according to lithology into two members, the lower consisting of marly limestone and gypsum, the thickness of this member is usually not fixed, gypsum exposures are expected to cause an engineering problem the dam foundation. The member is not exposed to any part of the proposed reservoir. In general, the thickness of these rocks ranges from (120) $\mathrm{m}$, except for limestone, its thickness reached $6 \mathrm{~m}$ [2]. The upper member, which exposed in the western and southwestern sides of the studied reservoir, consists of sequences of limestone, claystone, siltstone, and thin layers of gypsum [2] that are less dangerous on the foundations of dam and the reservoir, Figure 2. 


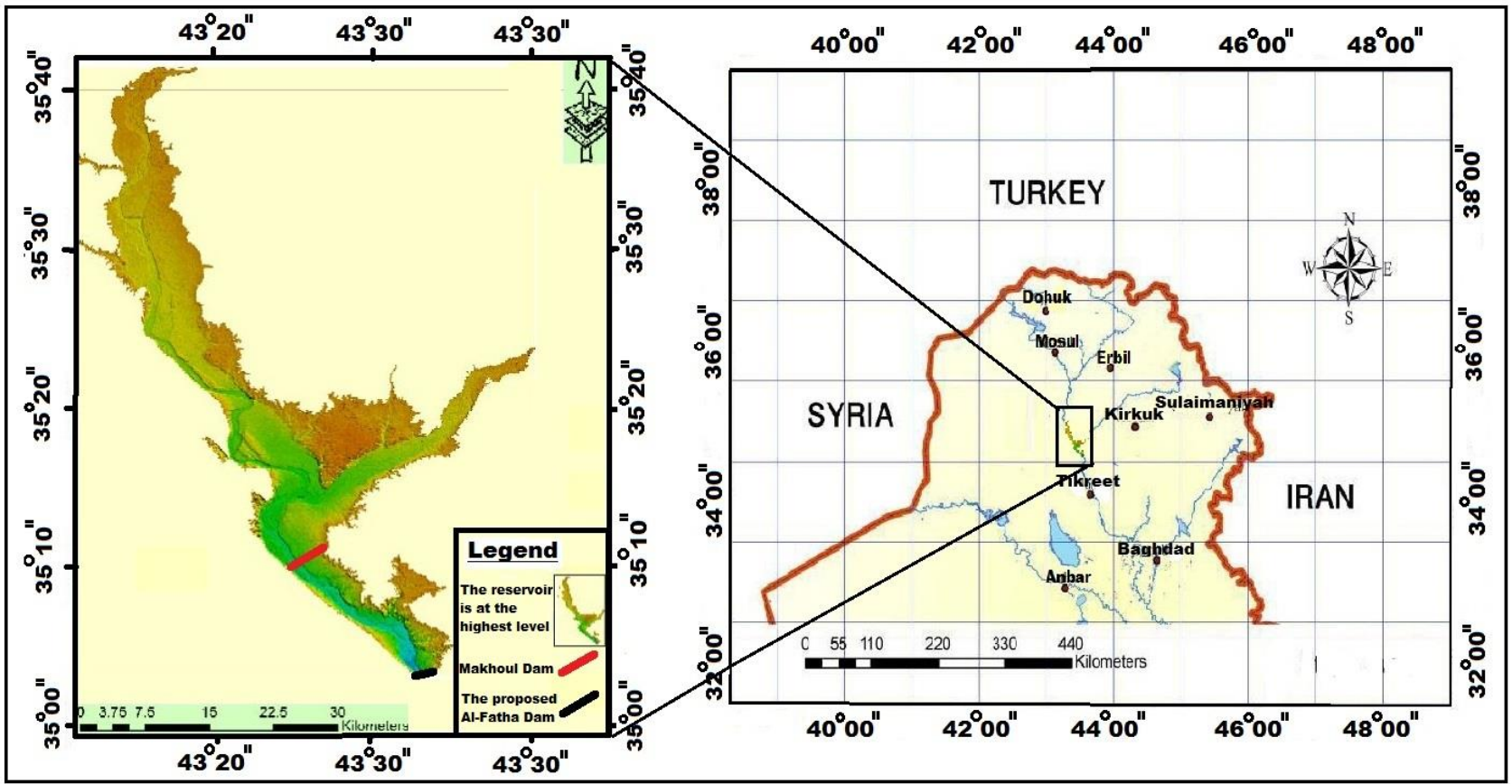

Figure 1. Location map of the study area.

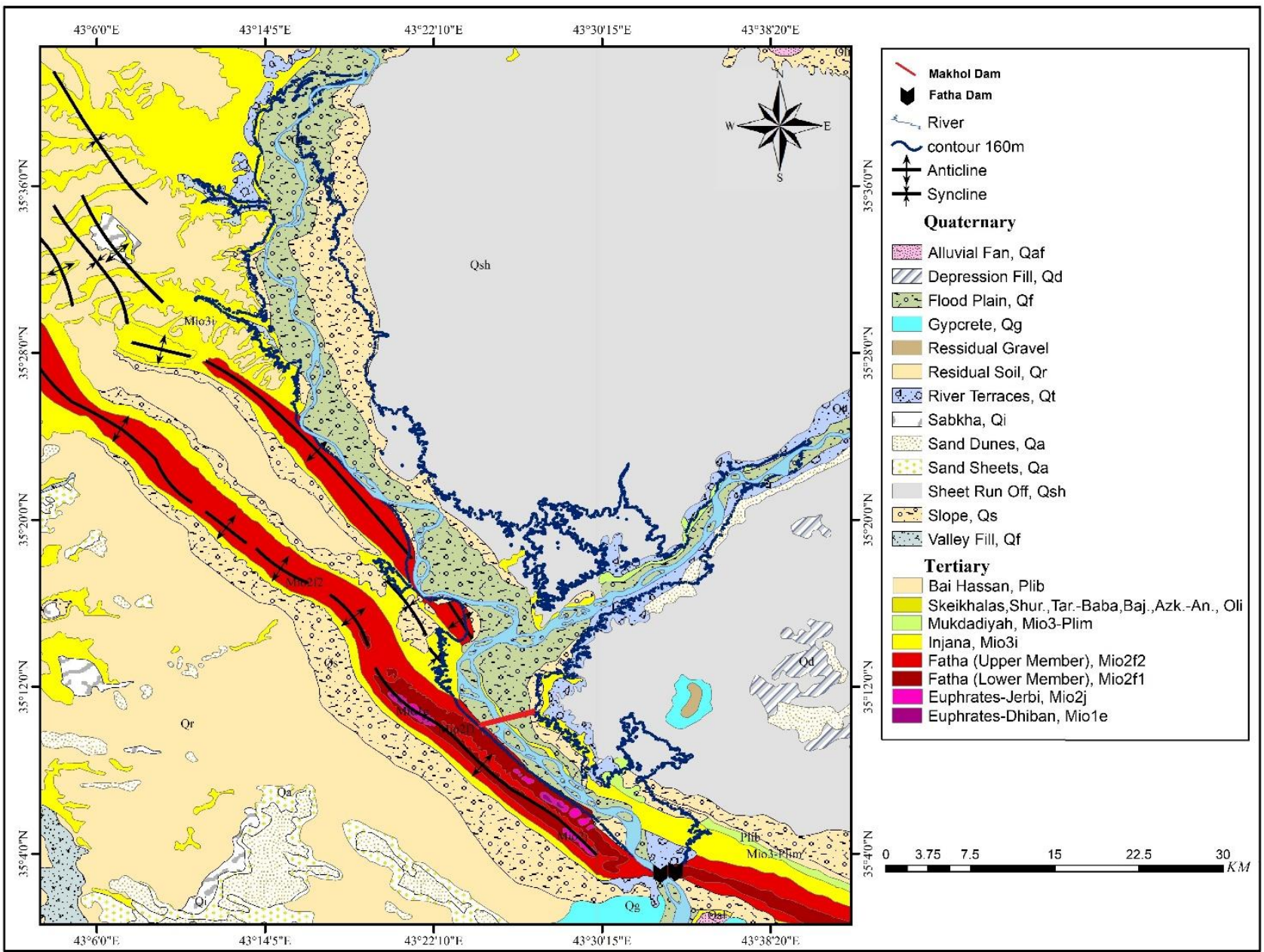

Figure 2. Geological map of the study area, modified after [10].

Injana formation (Upper Miocene-Pliocene) is conformable and overlay Fat'ha formation, Injana consists of sequences of sandy, silty, clayey, and other clastic alluvial layers or lenses of various thicknesses, while the total thickness of the formation ranges from $440-500 \mathrm{~m}$. The sedimentation 
environment of the formation is a coastal marine environment in the lower parts, while the upper part deposits in the fluvial continental depositional environment. Injana formation overlain by coarse terraces sediments belongs to the quaternary deposits located east of the Tigris river, including the river terraces (Pleistocene- Holocene), and these terraces are at different levels [3 and 4]. These deposits are sandy gravel, sand, silt, and clay, which rich in gypsum contents as a cement material in the upper parts in the north of the dam site, which may cause future engineering problems because of dissolution of gypsum, and require engineering treatments in order to avoid this problem [5].

Structurally, the main structures in the area are Makhul and Khanoga anticlines on the western bank of the reservoir; these two folds control the shape and extensions of the reservoir, the northern plunge of Hamrin anticline on the eastern side where the foundations of the eastern dam shoulder located. According to the division, the study area lies within the Hemrin-Makhul belt, which belongs to the range of the low folded zone [6]. This belt represents the boundary between the stable shelf and non-stable shelf, which is characterized by thick sedimentary cover and t. The asymmetric Makhul anticline is double plunges and extends towards the northwest-southeast parallel to Zagros series, and the northeast limb of the fold was inclined in a range (10-60) degree toward the northeast, while its southwestern limb was inclined by (30-70) degree towards southwest [7]. The area is characterized by the presence of fractures, joints, cracks, and veins [8]. These folds control the final shape of the river stream as low plain surrounded by high land to the west, where the river turned eastwards where Ziwiya and Namil villages are located [9]. Then, these folds will control the final shape of the reservoir. Geometric analysis is necessary to estimate the effect of reservoir sedimentation that reduces the reservoir's storage capacity [11].

The reservoir geometry affects the flash flood's peak discharge due to a dam collapse. The crosssection index of the reservoir also influences the flood discharge. These results were also confirmed by [12] that focused on reservoir geometry on peak discharge resulting from collapse. Taskin and Irveme [13] explain that reservoirs' estimation of volume and water surface area is essential to detect the available water, storage site, and storage capacity. They used Digital Elevation Model (DEM) and GIS in Turkey to study Orontes river basin. They found thirteen suitable sites for reservoir construction, by considering mainly narrow, deep valleys, minimum ecological and environmental disturbance, high elevations, a watertight reservoir area, no geological hazards, and potential of water yield. Halawa [9] dealt with the effect of the flood wave resulting from the collapse of a Cotton dam, the importance of studying the effect of the flood wave resulting from possible dam's collapse was identified, and the areas, height, and time of immersion were estimated, and the drawing of the flooded areas was prepared.

The study and analysis of the flood wave resulting from a hypothetical breakdown of the Kudnah dam on the valley of Raqqad in the Quneitra station using the (HEC-RAS) software were achieved [14]. In this reservoir, the scenarios of expected collapse and the most dangerous scenario were discussed. The arrival time of the flood wave to each cross-section was determined, then the area that is being flooded was estimated as 400 hectares. A new proposed methodology of geometric analysis was applied to Makhul dam reservoir [15] and then applied to analyze Wind dam reservoir in eastern Iraq [16]. This methodology used to select the optimum levels and the corresponding storage capacities for these reservoirs and then compare the results with the storage capacities that are calculated by traditional methods, so the operation scenarios for these reservoirs are proposed. The mentioned methodology was modified in the present study to simulate the hypotheses of Makhul dam break and exam the response of Al-Fat'ha dam. The present study aimed to extract the geometrical elements from the Digital Elevation Model (DEM) of Al- Fat'ha protecting dam and analyze the relationships between these elements, and then simulate the behavior of Al-Fat'ha dam when the hypothetical collapse of Makhul dam occurred.

\section{Methodologies}

The present work includes three stages:

1) The geometric analyses of Al-Fat'ha reservoir with the assumption of existence and operation of Makhul dam. 
2) Repetition of geometric analyses of Al-Fat'ha dam reservoir with the assumption of collapse of Makhul dam.

3) The scenarios of hypothetical collapse of Makhul dam.

Two methodologies were suggested in this study;

1) DEM-based methodology to achieve the $1^{\text {st }}$ and $2^{\text {nd }}$ stages of geometric analysis.

2) The second methodology to simulate the $3^{\text {rd }}$ stage above.

The main geometric elements derived are negative and positive volume; negative and positive surface area, negative and positive plane areas; and water level. The geometric analysis can summarize in the following steps:

1) The software (Global Mapper.13) was used to extract the DEM within the area of the reservoir limits at the level (118.5) $\mathrm{m}$ (a.s.1), which represents the higher level of Al-Fat'ha dam reservoir under the operation conditions, and exported as the form of (Global Mapper Package file).

2) Contour lines were generated from the DEM of the dam site for the operational levels (113 to 118.5) $\mathrm{m}$ (a.s.l), with contour interval (0.5) $\mathrm{m}$.

3) The extracted data by (Global Mapper. 13) was exported as (Surfer Grid file) which is required to generate the volume - Area data GRID by the software (Surfer. 13),

4) The geometric elements data obtained from the (Surfer.13) were tabulated by (Excel) to create the relationships between the different elements and the selected water levels.

5) The same steps above repeated for the levels (113 to 160) $\mathrm{m}$ (a.s.1), with contour interval (0.5) $\mathrm{m}$, to analyze the relations of geometric elements in the assumed case of Makhul dam collapse.

In the second methodology, fourteen scenarios were applied to simulate and analyze the hypothetical collapse of Makhul storage dam to:

1) Predict the behavior and ability of Fat'ha protecting dam to avoid the probable flood wave resulting from the breakdown.

2) Estimate the accumulative storage capacity in protecting dam reservoir for each scenario.

3) Determine the water level achieved for each storage capacity in the protecting dam reservoir.

4) Forecast the areas of village's that will submerge under the influence of flood for each scenario.

5) Total areas that will be subjected to immersion due to different scenarios of collapse were estimated.

\section{Result and Discussion}

The Geometric Analysis of The Reservoir. Geometric analysis studies in Iraq and the world are very limited, but some local studies may be helpful in the current study. Relationships between the geometric elements and water level, and between each, are essential in geometric studies. It is possible by these relationships to predict the changes that may occur on the ground surface after the beginning of the storage [17]. In addition, to determine the exposures of geological formations that may be submerged when the water level is raised in the reservoir. According to these relations, the safe level that ensures safe operation of the reservoir has been determined in proportion to the least harmful land uses and least submerged area and less contact with the geological formations of lithological content that could cause engineering problems or lead to a deterioration in the quality of the stored water. The geometric element, of levels from (113-118.5) $\mathrm{m}$ (a.s.1), with interval $0.5 \mathrm{~m}$ were derived from the digital elevation model, and their values are tabulated in Table 1. 
Table 1. Corresponding geometric elements for each reservoir selected levels.

\begin{tabular}{|c|c|c|c|c|c|c|c|c|c|}
\hline $\begin{array}{c}\text { Level m } \\
\text { (a.s.l) }\end{array}$ & $\begin{array}{c}\text { VI (Pos. } \\
\text { volume) } \\
\text { m }^{3}\end{array}$ & $\begin{array}{c}\text { RC (Neg. } \\
\text { volume) } \mathrm{m}^{3}\end{array}$ & $\begin{array}{c}\text { FAI (Pos. plane } \\
\text { area) } \mathbf{m}^{\mathbf{2}}\end{array}$ & $\begin{array}{c}\text { FARB (Neg. } \\
\text { plane area) } \\
\text { m }^{2}\end{array}$ & $\begin{array}{l}\text { UAI (Pos. } \\
\text { surface } \\
\text { area } \mathbf{m}^{2}\end{array}$ & $\begin{array}{c}\text { UARB (Neg. } \\
\text { surface area) } \\
\text { m }^{2}\end{array}$ & $\underset{\mathbf{m}}{\mathbf{A R D}}$ & $\underset{\mathbf{m}}{\mathbf{A I T}}$ & $\begin{array}{c}\text { Residual } \\
\text { volume } \mathbf{m}^{3}\end{array}$ \\
\hline 113 & 355652 & 1347534 & 328118 & 1484235 & 328331 & 1484402 & 0.9 & 1.08 & 37896053 \\
\hline 113.5 & 292005 & 2637448 & 230952 & 2370961 & 231198 & 2371270 & 1.1 & 1.26 & 36606139 \\
\hline 114 & 203808 & 4050294 & 141915 & 2711069 & 142152 & 2711569 & 1.5 & 1.44 & 35193293 \\
\hline 114.5 & 145226 & 5776948 & 108866 & 3293713 & 109053 & 3294370 & 1.8 & 1.33 & 33466639 \\
\hline 115 & 102567 & 7905901 & 161688 & 4113580 & 161809 & 4114432 & 1.9 & 0.63 & 31337686 \\
\hline 115.5 & 1739238 & 10699108 & 1201889 & 5390567 & 1202392 & 5391929 & 2.0 & 1.45 & 28544479 \\
\hline 116 & 1199820 & 13637281 & 1037718 & 6061591 & 1038019 & 6063143 & 2.2 & 1.15 & 25606306 \\
\hline 116.5 & 795285 & 17228193 & 823771 & 6761862 & 824101 & 6764182 & 2.5 & 0.96 & 22015394 \\
\hline 117 & 416407 & 20718359 & 608601 & 7203197 & 608756 & 7205558 & 2.9 & 0.68 & 18525228 \\
\hline 117.5 & 403798 & 26150441 & 612429 & 10570650 & 612597 & 10573631 & 2.5 & 0.65 & 13093146 \\
\hline 118 & 152328 & 31871014 & 323854 & 11525942 & 323925 & 11529255 & 2.8 & 0.47 & 7372573 \\
\hline 118.5 & 1419975 & 39243587 & 1140016 & 14119091 & 1140467 & 14123632 & 2.8 & 1.24 & 0 \\
\hline
\end{tabular}

VI: Volume of Islands, RC: Reservoir Capacity, FAI: Flat area of Islands, FARB: Flat area of reservoir bed, UAI: Undulated area of Islands, UARB: Undulated area of reservoir bed, ARD: Average reservoir depth and AIT: Average islands thickness, Pos.: positive, and Neg.: negative.

The Relationship of The Water Level to The Islands Positive Volume. The islands within the border of the reservoir represent the tops of former hills; fluctuations in the water level greatly affect the number, location, and size of these observed islands [18]. It has been observed from Figure 3A that there is a high fluctuation of positive volume with the fluctuation of water level. This relationship showed a decrease of positive volume with an increase of water levels from 113 to $15 \mathrm{~m}$ (a.s.l), and the highest growth occurs at the level of $115.5 \mathrm{~m}$ (a.s.l) (positive volume 1739238) $\mathrm{m}^{3}$. The reason for this is the addition of new islands on the reservoir as islands. Then the positive volume decreased gradually toward the level $118 \mathrm{~m}$ (a.s.1), (positive volume 152329) $\mathrm{m}^{3}$. An increase occurs at a level (118.5) $\mathrm{m}$ (a.s.l) (positive volume (1419975) $\mathrm{m}^{3}$, as a result of adding new islands, and the reason for this exceptional increase is the appearance of a new group of islands within the reservoir. This is an important determining factor in future land uses, as in Figure 3A.
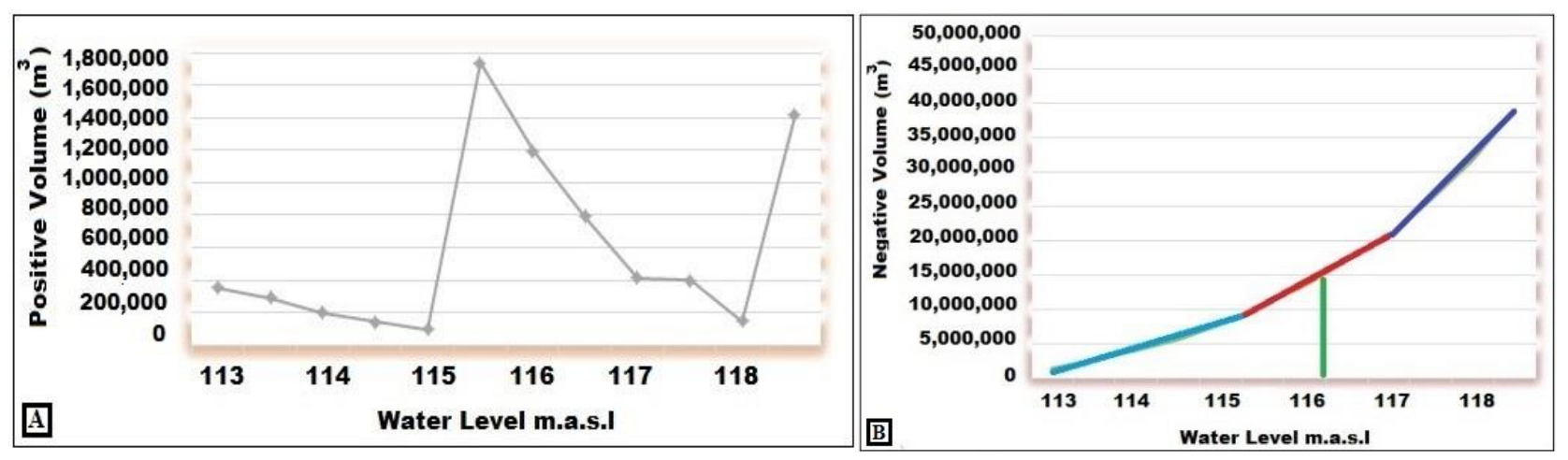

Figure 3. Relationships between water level and islands positive volume (A), and between water level and negative volume or storage capacity (B) of the reservoir.

The Relationship of The Water Level to The Negative Volume of The Reservoir. The Global Mapper program provides great possibilities for deriving dam reservoirs' capacities and their surface areas from the digital elevation model (DEM) with high accuracy and ease [19]. This is what was applied in this study, as shown in Figure 3B the increase in the negative volume with increasing water level, in general, the direction of this relationship is divided into three stages: The first begins with the beginning of storage at the level (113) $\mathrm{m}$ (a.s.l), where the storage reached to (1347534) $\mathrm{m}^{3}$ and ended at the level $(115) \mathrm{m}$, where the estimated capacity is about (7905901) $\mathrm{m}^{3}$, where the increase in the volume of the reservoir at this stage is slight with an increase in the level. While the transitional stage begins at the level in $115.5 \mathrm{~m}$ (a.s.l) and ends at the level (117) $\mathrm{m}$, where the capacity is about $(20718359) \mathrm{m}^{3}$, notice the gradual increase being more than the first stage, while the last stage begins 
at the level (117) $\mathrm{m}$ (a.s.1), to (118.5) $\mathrm{m}$ (a.s.1), which correspond to the negative volume (39243587) $\mathrm{m}^{3}$. It's noted that the increase in this stage is more than the two previous stages. Most of the river islands are submerge in addition to the emergence of new islands. The transition from one stage to another occurs due to the transition of storage from the original river cliff to the flood plain and then to the river terraces in the last stage, as shown in Figure 3B.

The Relationships of The Water Level to The Positive Surface Area and Positive Plane Area. The relationships of the water level to the positive surface area and positive plane area. The existence of islands within the reservoir boundaries has importance, especially in determining the class of land use, as they often represent tourism attractions areas. On the other hand, these islands may be eroded, and then the friable sediments transported downstream to cause engineering problems in front of the dam gates, but sometimes the area of islands grows gradually with time [20]. The positive surface area (undulated area) of the islands within the reservoir borders is relatively limited below the level (115.5) $\mathrm{m}$, where the reservoir boundaries are still within the original reach of the river. But, this area increases sharply at this level, and returns directly to decrease gradually, then increases at the maximum operating level (118.5) $\mathrm{m}$ (a.s.1) as shown in Figure 4A.

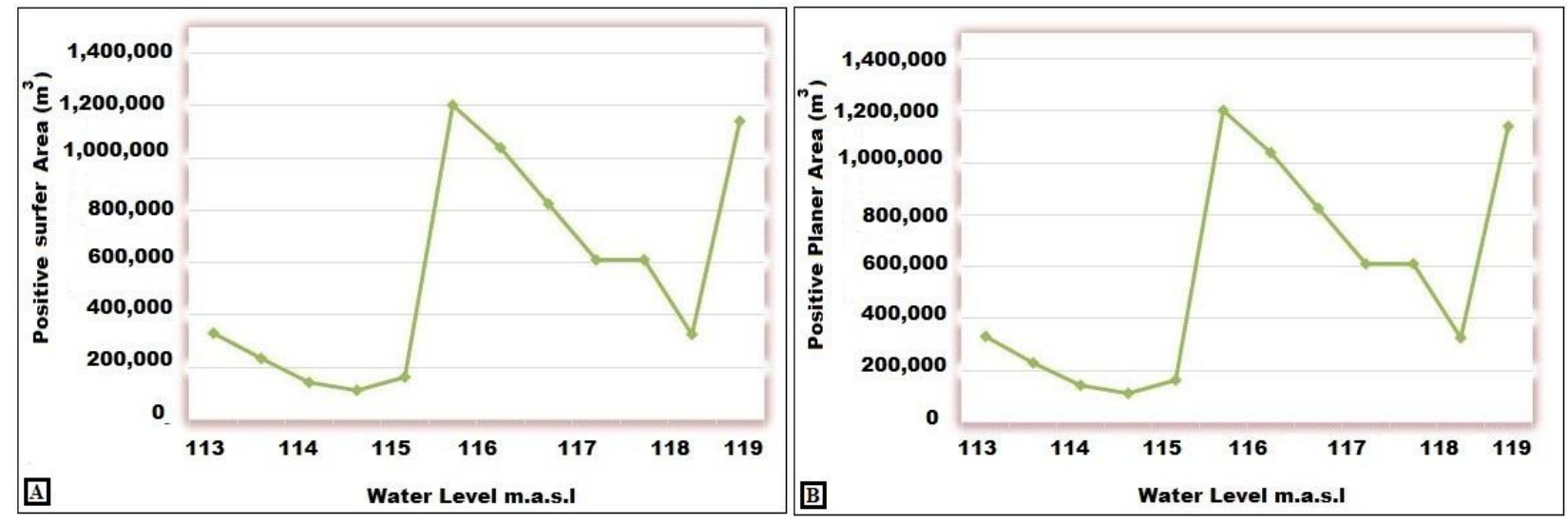

Figure 4. Relationships between water level $\mathrm{m}$ (a.s.l) with positive surface area (A), and between water level with a positive plane area of islands (B).

The positive planner area (a flat area of islands) appears similar to the positive surface area because of the same reasons for the emergence or submergence of islands, Figure 4B. There are two reasons for the high similarity in the curve of the positive planner area and the positive surface area. The first is low roughness of topography of the area so that the planner area is similar to the surface area. The second is the low resolution of the digital elevation model (DEM).

Relationship of Water Level with Negative Surface Area (Reservoir Bed Area). Its notice that the negative surface area (undulated submersed area) in Figure 5A increases continuously with the increase of the level, and the slope of the increasing curve is gradual in the initial levels. However, it increases sharply after the level (117.5) $\mathrm{m}$ (a.s.l) due to the exit of the reservoir out of the original river cliff.

\section{Relationship of The Water Level with The Negative Plane Area (Flat Exposed Area of Water} Body). The exposed flat area of the reservoir indicates the losses by evaporation; therefore, its estimation at each level can ease the estimation of evaporation [21] and select the optimal operating level of the reservoir. The flat exposed area of the water body appears similar to the negative surface area (reservoir bed submersed area), as shown in Figure 5B. There are two reasons for the high similarity in the curve of the negative planner area and the negative surface area. The first is the low roughness of topography of the submersed area, so that the planner area is close to the surface area. Second is the low resolution of digital elevations model (DEM). 

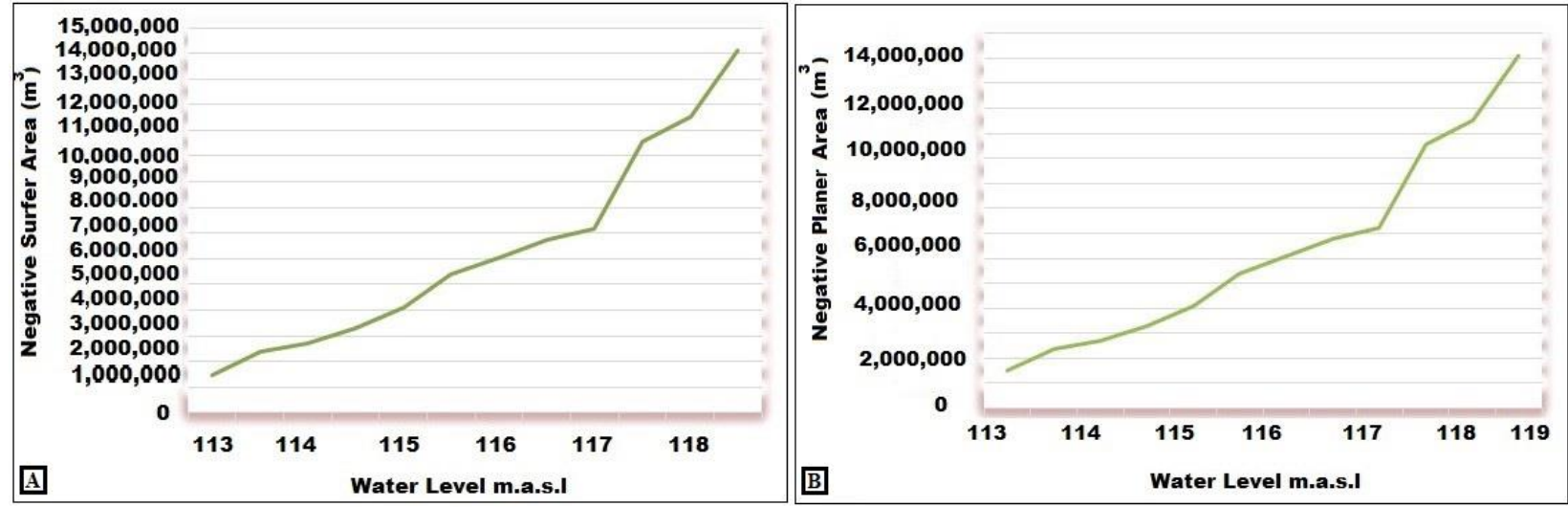

Figure 5. Relationships between water level and soaked surface area (A), and between water level and flat area $(\mathrm{B})$.

Relationship of Water Level and Average Depth of Reservoir. The average depth is an important factor in selecting the location of the reservoir. It gives a general idea of the reservoir conditions and usually chooses the site as deep as possible [22]. Through the relationship between the level and the average depth, it was found that the average depth increases with increasing the level, and the curve shape is similar, where it's (0.9) $\mathrm{m}$, at the level of (113) $\mathrm{m}$ (a.s.l), and it's increased with increasing the level to reach (1.5) $\mathrm{m}$ when the level is (114) $\mathrm{m}$ (a.s.l). At the level (115) $\mathrm{m}$, the depth reaches (1.9) $\mathrm{m}$, as shown in Fig.6A. Then, the increasing continuous to reach (2.9) $\mathrm{m}$ at the level of (117.5) $\mathrm{m}$, while at the level $(118.5) \mathrm{m}$, the average depth slightly decreased to (2.8) $\mathrm{m}$ because of the increase of shallow areas in this level in the reservoir compared to the deep ones, as shown in Table 1.
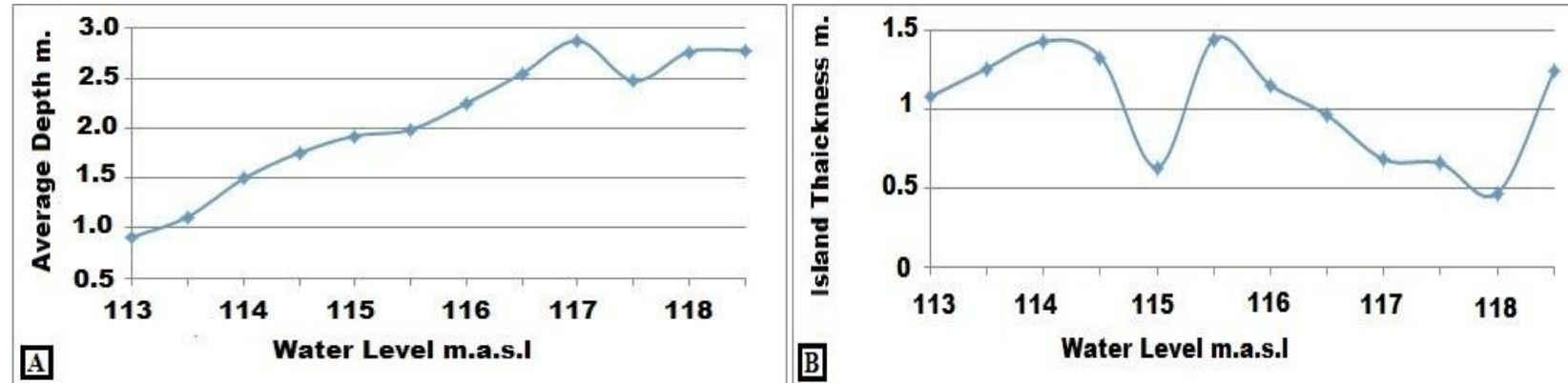

Figure 6. Relationships between water level with an average depth of reservoir (A) and water level with an average thickness of islands (B).

Relationship of water level and average thickness of islands: The relationship between the level and average thickness of islands reflect the fluctuation of average thickness, which reached $1 \mathrm{~m}$ where the level of (113) $\mathrm{m}$ (a.s.1), then, is increased to $1.4 \mathrm{~m}$. at the level (114) $\mathrm{m}$ (a.s.1), which represents the most significant average thickness of islands in the proposed reservoir, then decrease at the level (115) $\mathrm{m}$ (a.s.1), and then the average thickness is reduced to reach $(0.5) \mathrm{m}$ where the level $(117-118)$ $\mathrm{m}($ a.s.1), Figure 6B.

Relationships of Geometric Elements when the Expected Collapse of Makhul Dam Occurs. For conducting the geometric analysis and the relationships between the geometric elements assume the collapse of Makhul dam, in this study, the geometric elements corresponding the levels 113 to $160 \mathrm{~m}$ (a.s.l) with an interval of (0.5) $\mathrm{m}$ was derived from digital elevation model and tabulated in Table 2. 
Table 2. the values of corresponding geometric elements for each reservoir selected water levels, when the expected collapse of Makhul dam, in metric units.

\begin{tabular}{|c|c|c|c|c|c|c|c|c|c|}
\hline $\begin{array}{c}\text { Level } \\
\text { m } \\
\text { (a.s.l) }\end{array}$ & $\begin{array}{l}\text { VI (Pos. } \\
\text { volume) } \\
\text { m }^{3}\end{array}$ & $\begin{array}{l}\mathrm{RC}(\mathrm{Neg} . \\
\text { volume) } \mathbf{m}^{3}\end{array}$ & $\begin{array}{c}\text { FAI } \\
\text { (Pos. plane } \\
\text { area) } \mathbf{m}^{2}\end{array}$ & $\begin{array}{c}\text { FARB } \\
\text { (Neg. plane } \\
\text { area) } \mathbf{m}^{2}\end{array}$ & \begin{tabular}{|c|} 
UAI \\
$($ Pos. \\
surface \\
area) $\mathbf{~ m}^{2}$ \\
\end{tabular} & $\begin{array}{r}\text { UARB } \\
(\text { Neg. } \\
\text { surface } \\
\text { area) } \mathbf{~ m}^{2} \\
\end{array}$ & $\begin{array}{c}\text { ARD } \\
\mathbf{m}\end{array}$ & $\begin{array}{c}\text { AIT } \\
\text { m }\end{array}$ & $\begin{array}{c}\text { Residual } \\
\text { volume } \\
\mathbf{m}^{3}\end{array}$ \\
\hline 113.0 & & & & & 328332 & $1,484,402$ & 0.91 & 1.08 & 53 \\
\hline & & & & & & & 1.11 & 1.26 & \\
\hline & & & & & & & 1.49 & 1.44 & \\
\hline & & & & & & & 1.75 & 1.33 & \\
\hline$x_{2}+2$ & & & & & & & 1.92 & 0.63 & \\
\hline 115.5 & 13 & & $1,201,090$ & $\mathrm{~J}$, & $1,202,392$ & $5,391,929$ & 1.98 & 1.45 & 8,2 \\
\hline$\downarrow$ & & & & & & & $\downarrow$ & $\downarrow$ & \\
\hline 159.5 & 096, & 0 & +1 & 328 & $28,437,705$ & $532,179,581$ & 14.95 & 2.18 & 788234 \\
\hline 160.0 & $49,028,893$ & $8,218,858,070$ & $25,179,846$ & $545,421,252$ & $25,193,038$ & $545,960,661$ & 15.07 & 1.95 & 0 \\
\hline
\end{tabular}

Data of the column form (1-7) where taken from reports of the grid files of the surfer program, issued by data on the digital height for the reservoir under study.

Relationship of Water Level with Reservoir Capacity (Negative Volume). Al-Ansari et al. [23] recommended that the protection dam is the best solution to protect from the flood wave that may result from the collapse of the Mosul dam with a similar geotechnical condition Makhul dam. Accordingly, estimating the storage capacity of the protection dam reservoir at different levels is very important to predict the appropriate level at which the protection dam can receive the flood wave resulting from the collapse of Makhul dam, and this is the main goal of the present study. Figure 7A noticed that the negative volume increases with the increase of water level, where three stages could be found from this relationship. Two essential stages were parted by the transitional one. The first from the levels (113-134) $\mathrm{m}$ (a.s.1), when the reservoir volume slightly increased and reach $(1,347,534) \mathrm{m}^{3}$ to $(810,482,564) \mathrm{m}^{3}$ respectively, while in the transitional stage at the levels $(134-$ 146) $\mathrm{m}$ (a.s.1), where the storage volume reached to $(2,884,919,109) \mathrm{m}^{3}$, it's noticed that the increase of storage capacity was gradual and sharper than the first stage. The last stage, at level (146-160) $\mathrm{m}$ (a.s.1), when the corresponding storage $(8,218,858,070) \mathrm{m}^{3}$. it is noticed that the increase in this stage was sharpest than the first and transition stages, most of the islands will submerge, in addition, to appear of new islands, these stages happen due to exit of the storage from the original river cliff to the flood plain, and then to the river terraces, as in Figure 7A.
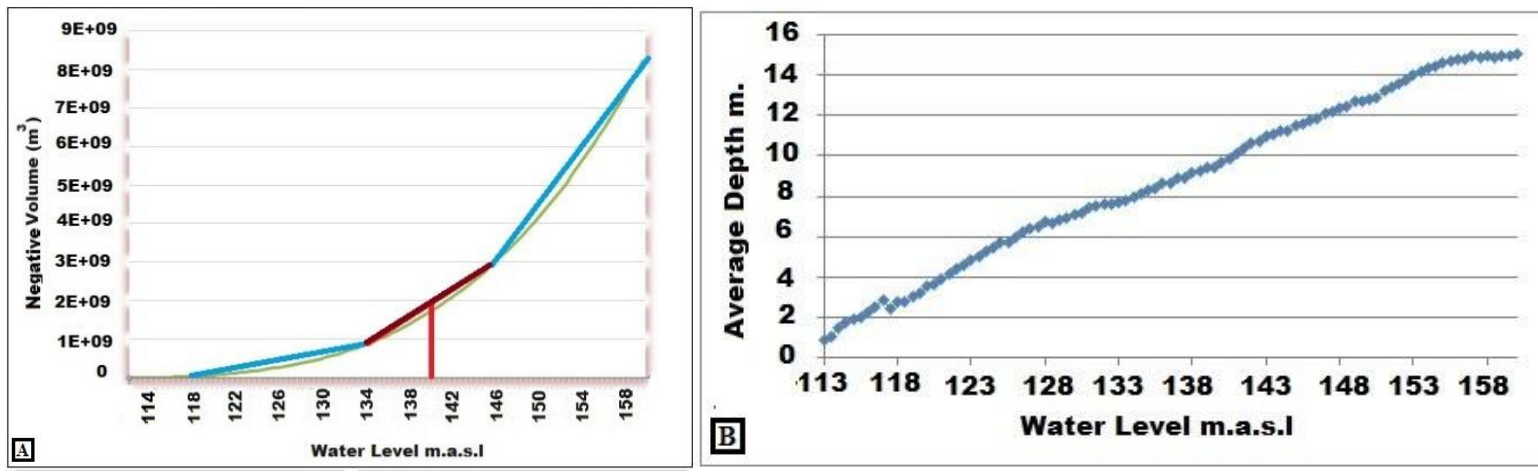

Figure 7. Relationships between proposed water level with negative volume (A), and between water level with an average depth of the reservoir (B).

The Relationship Between the Water Levels and The Average Depth of The Reservoir. The decrease in the average depth with an increase in the level means adding large shallow areas to the reservoir [24]. It was found that the average depth increases with increasing the water level, where the depth rate ranges from $0.9 \mathrm{~m}$ to $2.9 \mathrm{~m}$ at the level 113 to $118 \mathrm{~m}$ (a.s.l), respectively. The increase 
is gradually continuing to the level of $160 \mathrm{~m}$. Then the depth will be (15.1) $\mathrm{m}$, which represents the most significant depth of the reservoir depth, as shown in Fig.7B.

The relation of the level with negative surface area and negative planner area: To select the optimal water level of the reservoir, it must be taken into account that the flat area of the water body and the submerged area of the bottom of the reservoir be as low as possible, to minimize the losses by evaporation or seepage [25]. The negative surface area (undulated area of reservoir bed) represents the uneven area of the wetted ground or the area of seepage. It is noticed through Figure 8A, which the negative surface area value increases continuously with increasing the level. The slope of the increase curve is low where the initial levels. However, the curve slope is sharply increased where the reservoir leaves the original river stream to the flood plain.
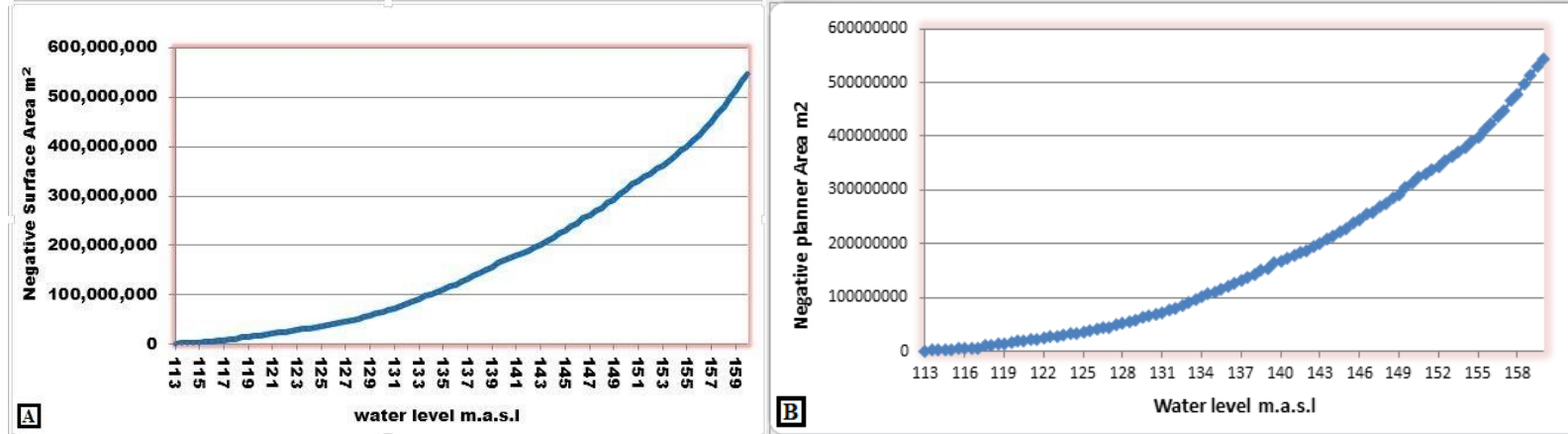

Figure 8. Relationships between water level with negative surface area (A) and between water level with a negative flat area (B).

Relationship of the Water Level with Negative Planner Area. The negative planner area (area of losses by evaporation), which represents the flat area of the water body in the reservoir that is exposed to weather conditions, note that the value of the negative planner area increases continuously and is not fluctuating with an increase of the level. Through Figure 8B the low slope of the curve where the low levels, but the slope of the curve increases dramatically after the level (119.5) $\mathrm{m}$ (a.s.l) due to the leave of reservoir body from the original river stream to the flood plain.

Scenarios for Hypothetical Collapse of Makhul Dam. Many authors have simulated the effects of flood waves resulting from the collapse of dams [26], but who simulated the response of protection dam to the hypothetical collapse flood wave are limited, the present study simulates the response of Al-Fat'ha dam to the hypothetical flood wave resulting from the collapse of Mosul dam. Digital Elevation Models (DEM) were separated for the reservoir location, and a geometric analysis was performed. The relationship between reservoir volume and the water level was derived, in addition to calculating the negative planner area and negative surface areas, in order to be used in the analysis of the collapse hypothesis of Makhul dam. In addition to the geometrical elements that were used in the collapse hypothesis, which are the selected level, the volume of water in the reservoir when the moment of collapse, and the remaining empty volume in the reservoir that will be used to receive the additional storage during the hypothetical failure. Fourteen hypothetical scenarios for the collapse were proposed to calculate the cumulative storage and the corresponding level resulting from this storage Al-Fat'ha protecting dam reservoir for each scenario, to demonstrate the ability of this dam to receive the maximum (hardest) scenario of a possible collapse of Makhul dam, the results of collapse hypothesis are tabulated in Table 3.

Assumptions for different collapse scenarios of Makhul dam: These hypotheses are the basis for a new methodology for analyzing the collapse of Makhul dam, based on the data of geometrical analysis of Al-Fat'ha and Makhul dam's reservoirs after the supposed collapse.

Assumption-1. The protecting dam (Al-Fat'ha) must receive the maximum volume that Makhul dam can release when the moment of collapse, which is estimated at about (3375062182) $\mathrm{m}^{3}$, which 
corresponds to the level (152.15) $\mathrm{m}$ (a.s.l) in Makhul dam, in addition to the volume of storage in AlFat'ha Protecting dam reservoir at its maximum operational level.

Assumption-2. Before collapsing, the discharge entering the protecting dam (Al-Fat'ha) is the same discharge exiting from the gates, spillway, fish passage, and other outlets from Makhul dam.

Assumption-3. The reserve inside the protecting dam (AlFat'ha) when the moment of Makhul dam collapse, is the volume of reservoirs at the maximum operational level of the dam (118.5) $\mathrm{m}$ (a.s.l), according to geometrical analysis, the volume of water corresponding to this level is (39243587) $\mathrm{m}^{3}$.

Assumption-4: To take into account all the possibilities that could occur when Makhul dam collapsed, fourteen scenarios were supposed for assumed water levels in Makhul dam reservoir when the moment of collapse, from 140 to 152.15 , with a one-meter interval between level to another.

Assumption-5: Neglecting the amount of water that withdrawn from the Tigris River between Makhul dam and the Protecting dam (Al-Fat'ha) used for irrigation and industrial purposes, as the rationale for this hypothesis is that there is no need for irrigation during the flood period, which is the same period of heavy rains, as well as the stopping of all Industrial pumps due to the high turbidity and the difficulty of treating them during this period.

Assumption-6: When Makhul dam collapses, it must be taken into account that the out-discharge Al-Fat'ha Protecting dam at the maximum possible Discharge.

Assumption-7: The occurrence of flooding in Baiji and reaching the level of destruction means the occurrence of destructive flooding in the sections of the river downstream (Tikrit, Samarra, etc.), and vice versa [27].

Mathematical model to predict the water level by accumulated storage in protecting dam: Mathematical relationship was derived to determine the level that results from the accumulated storage in Al-Fat'ha Protecting dam, after the complete collapse of Makhul proposed dam, to predict the ability of Al-Fat'ha dam to receive the maximum collapse scenario of Makhul dam. Eq. 1 shows the relationship between the cumulative storage (on $\mathrm{x}$-axis) and the corresponding level by that storage (on y-axis), see Figure 9.

$$
\mathrm{Y}=2.37 \times 10^{-47} \mathrm{X}^{2}-5.29 \times 10^{-37} \mathrm{X}^{4}+4.36 \times 10^{-27} \mathrm{X}^{3}-1.65 \times 10^{-17} \mathrm{X}^{2}+3.2 \times 10^{-8} \mathrm{X}=117.2
$$

Where

$\mathrm{X}=$ cumulative storage in the reservoir in $\left(\mathrm{m}^{3}\right)$.

$\mathrm{Y}=$ the level achieved in the reservoir because the effect of the cumulative storage (m (a.s.l)).

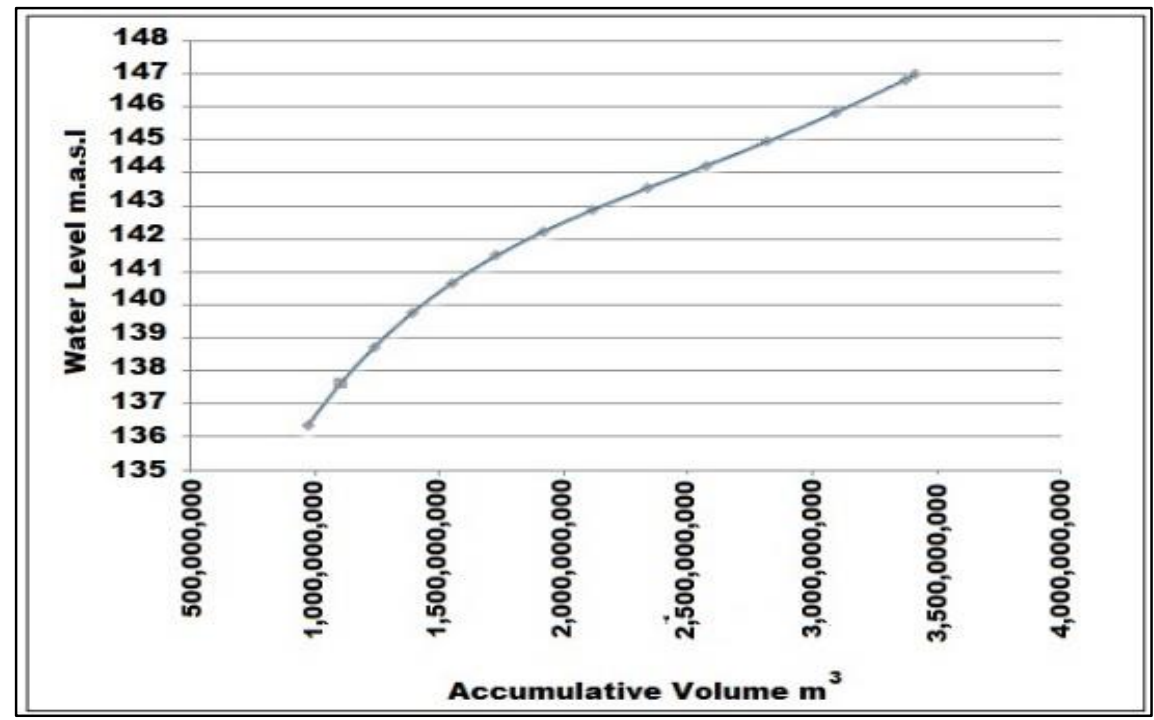

Figure 9. Relationship between cumulative storage in Al-Fat'ha protecting dam and water level achieved in the reservoir after Makhul dam collapse. 
Table 3. EXCEL program to process the data of different Scenarios of collapse of Makhul dam.

\begin{tabular}{|c|c|c|c|c|c|c|c|}
\hline $\begin{array}{c}\text { Initial } \\
\text { Storage in } \\
\text { Al-Fat'ha } \\
\text { dam } \mathbf{m}^{3}\end{array}$ & 胥 & $\begin{array}{c}\text { Level in } \\
\text { Makhul dam } \\
\text { when the } \\
\text { collapse m }\end{array}$ & $\begin{array}{l}\text { The volume of } \\
\text { Makhul dam } \\
\text { the collapse } \mathbf{m}^{3}\end{array}$ & $\begin{array}{l}\text { Accumulative } \\
\text { volume in Al- } \\
\text { Fat'ha dam } \text { m }^{3}\end{array}$ & $\begin{array}{c}\text { Level } \\
\text { achieved in } \\
\text { Al-Fat'ha } \\
\text { dam after } \\
\text { collapse m }\end{array}$ & $\begin{array}{c}\text { Additional } \\
\text { submerged area } \\
\text { m }^{2}\end{array}$ & $\begin{array}{c}\text { Total } \\
\text { submerged } \\
\text { area } \mathbf{k m}^{3}\end{array}$ \\
\hline \multirow{14}{*}{ 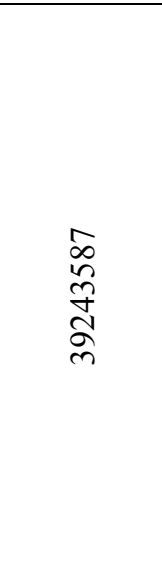 } & $1^{\mathrm{st}}$ & 140 & 932488454 & 971732041 & 136.34 & 27406342 & 28.818 \\
\hline & $2^{\text {nd }}$ & 141 & 1063324169 & 1102567756 & 137.60 & 28999610 & 30.411 \\
\hline & $3^{\text {rd }}$ & 142 & 1201119595 & 1240363182 & 138.73 & 30822492 & 32.234 \\
\hline & $4^{\text {th }}$ & 143 & 1350297299 & 1389540886 & 139.75 & 32253651 & 33.665 \\
\hline & $5^{\text {th }}$ & 144 & 1512401343 & 1551644930 & 140.67 & 33786296 & 35.198 \\
\hline & $6^{\text {th }}$ & 145 & 1688310308 & 1727553895 & 141.49 & 35360103 & 36.772 \\
\hline & $7^{\text {th }}$ & 146 & 1876914048 & 1916157635 & 142.22 & 35701193 & 37.113 \\
\hline & $8^{\text {th }}$ & 147 & 2080305103 & 2119548690 & 142.90 & 37700652 & 39.112 \\
\hline & $9^{\text {th }}$ & 148 & 2297597687 & 2336841274 & 143.55 & 37859643 & 39.271 \\
\hline & $10^{\text {th }}$ & 149 & 2531505683 & 2570749270 & 144.23 & 39814646 & 41.226 \\
\hline & $11^{\text {th }}$ & 150 & 2781433378 & 2820676965 & 144.97 & 40377441 & 41.789 \\
\hline & $12^{\text {th }}$ & 151 & 3050617730 & 3089861317 & 145.84 & 42107914 & 43.519 \\
\hline & $13^{\text {th }}$ & 152 & 3332428780 & 3371672367 & 146.84 & 42127809 & 43.539 \\
\hline & $14^{\text {th }}$ & 152.15 & 3375062182 & 3414305769 & 147.00 & 42617509 & 44.029 \\
\hline
\end{tabular}

Village Submerged by the Collapse of Makhul Dam. Fourteen scenarios were assumed for the collapse of Makhul dam. In the first collapse scenario, nine villages are submerged at the level 140 $\mathrm{m}$, including Breach, three-quarters of Al-Hassan Al-Bakri, Lower Tel Al-Thahab, and Upper Tel AlThahab, Al-Sada, Al-Musalakha, very few parts of Al-Salman, Al-Hawayij, and Mosa Al-Hory villages, Fig.10A. Al-Hassan Al-Bakri is completely submerged, and large parts of Al Salman village in the seventh collapse scenario as in Fig.10B, for the last submerge scenario, the village of Salman is completely submerged, Figure 10C.
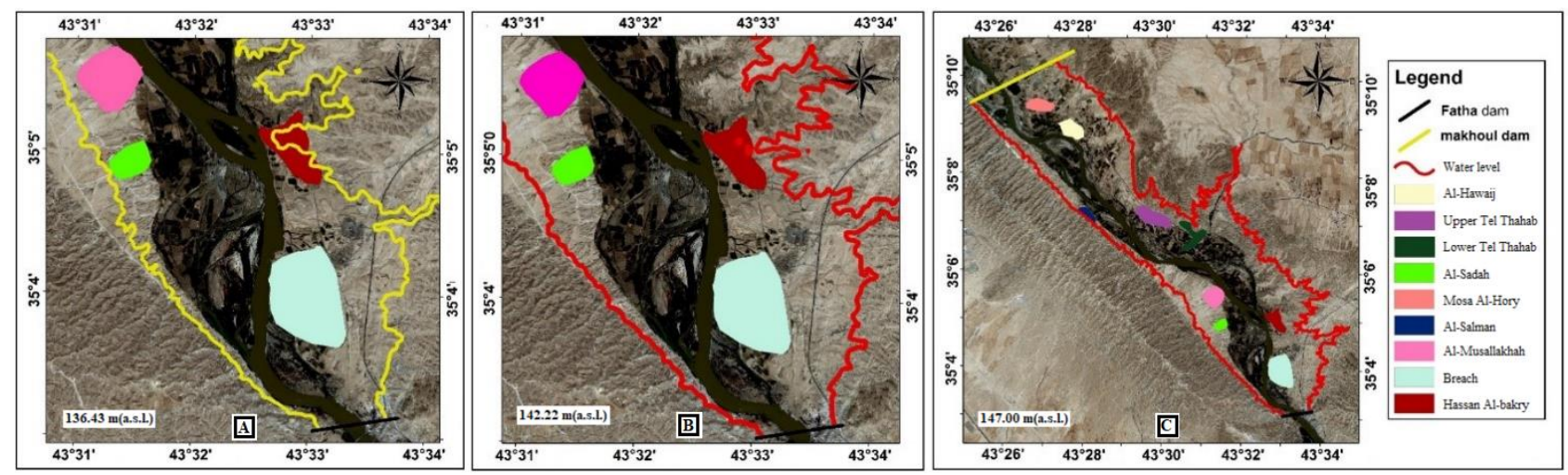

Figure 10. Villages which submerged at the first submersion scenario on $136.43 \mathrm{~m}(\mathrm{~A})$, the seventh scenario on $142.2 \mathrm{~m}(\mathrm{~B})$, and the last flood scenario on $147 \mathrm{~m}(\mathrm{C})$.

\section{Conclusions}

The results of the geometric analysis indicate the optimum operating level for Al-Fat'ha dam, in the usual operating conditions without the collapse of Makhul dam is $118.5 \mathrm{~m}$ (a.s.l), which corresponds to the capacity $(39243587) \mathrm{m}^{3}$. While the maximum level in the protecting dam reservoir to face the worst collapse, the scenario is $147 \mathrm{~m}$ (a.s.1), when the corresponding accumulated storage in the reservoir is $3414305769 \mathrm{~m}^{3}$. The total flooded area between the two dams was calculated for each collapse scenario of Makhul dam, it is about $44 \mathrm{~km}^{2}$ for the worst scenario, and then nine villages on the banks of the reservoir will submerse. So, the study confirmed the ability of Al-Fat'ha dam reservoir to receive the direct flood wave caused by the collapse of Makhul dam. 


\section{Reference}

[1] Hussain, A. I., 2009. Geomorphotectonic study for Makhul structure by using satellite data. Iraqi journal of science, 50(3). p-15.

[2] Jassim, S.Z. and Goff, J.C., 2006. Geology of Iraq. Published by Dolin, Prague and Moravian Museum, Brno. Printed in the Czech Republic.

[3] Jassim, S.Z., 1981. Early Pleistocene gravel fan of the Tigris river from Al Fatha to Baghdad, Central Iraq. J. Geol. Soc. Iraq, 14(1), pp 25-34.

[4] Kadhim, L. S., Ajeel, M. W. and Warid, A. H., 2009. Sedimentology and mineralogy studies of Quaternary sediment in Tikrit area. Proceeding of First Scientific Conference, College of Science, University of Tikrit, pp. 243-249.

[5] Al-Darraji, Z. T. A., 2011. Application of vertical electrical sounding to delineate and evaluate of aquifers characteristics in Baihi-Tikrit basin. Ph.D. Thesis, University of Tikrit, Iraq.

[6] Buday, T. and Jassim, S.Z., 1987. The Regional geology of Iraq, vol. 2: Tectonism, Magmatism and Metamorphism. GEOSURV, Baghdad, 352pp.

[7] Anon, 1994. Geological and Geotechnical Report for Makhul/2 Pump Storage Project. Report Scientific Consultant Bureau, Collage of Science, University of Baghdad.

[8] Mohammed, A, I, 2011. Geotechnical Properties of Limestone from Fat'ha Formation and Their Suitability for Building Stone and Railway Ballast at Fat'ha Area / North of Iraq M.Sc. Thesis, Tikrit University, Iraq.

[9] Halawa, L., 2009. Integrated management of the flood wave caused by the collapse of a dyke and the mitigation of its effects. Ph.D. Thesis, AL-Baath University, Syria.

[10] State Establishment of Geological Survey and Mining (GEOSURV), 1993. The Geological Maps of Iraq, Sheets No. I-38B/SW, I-38-B/SE, I-38-H/NW, and I-38-H/NE, scale 1:100000, Baghdad, Iraq.

[11] Adeogun, A.G., Ibitoye, B.A., Salami, A.W. and Ihagh, G.T., 2020. Sustainable management of erosion prone areas of upper watershed of Kainji hydropower dam, Nigeria. Journal of King Saud University-Engineering Sciences, 32(1), pp.5-10.

[12] Feizi Khankandi, A., Tahershamsi, A. and Soares-Frazão, S., 2012. Experimental investigation of reservoir geometry effect on dam-break flow. Journal of Hydraulic Research, 50(4), pp.376387.

[13] Taşkın, M. and İrvem, A., 2014. Reservoir location and capacity analysis using GIS in semiarid region. TABAD, Tarım Bilimleri Araștırma Dergisi, 7(2), pp.53-59.

[14] AL-Shublaq M. and Al Tijar, M., 2015. Analysis the flood wave resulting from a hypothetical breakdown of the Kudnah Dam using the (HEC-RAS) program. M.Sc. Thesis, Department of Water Resources Engineering, University of Damascus, Syria.

[15] Saleh, L. M, 2014. Makhool reservoir dam hydro geometric study to select the optimal level. Ph.D. Thesis, Tikrit University, Iraq.

[16] Qadir, I.T.A., Saleh, S.A., Ibrahim, A.M. and Hussain, H.M., 2018. Geometric Investigation of Al-Wind Dam Reservoir Northeastern Iraq, using Digital Elevation Models and Spatial Analyses System. Tikrit Journal of Pure Science, 23(3), pp.75-86.

[17] Barjasteh, A., 2019. Influence of geological structure on dam behavior and case studies. In Dam Engineering. IntechOpen.

[18] ABD ELLAH, R. and Tarek, E.L., 2016. Bathymetric Study of Some Khors in lake Nasser, Egypt. Lakes, Reservoirs and Ponds, 10(2), pp.139-158.

[19] Khasanov, Kh., Bakiev, M., Choriev, J., Jakhonov, A., and Khalimbetov, A., 2019. Water reservoir area and volume determination using geoinformation technologies and remote sensing. International Journal of Recent Technology and Engineering (IJRTE), Blue Eyes Intelligence Engineering and Sciences Publication, 8(4), pp. 5458-5461. 
[20] Danzeisen, V.L., 2016. Cottonwood (Populus Deltoides) recruitment in response to a large infrequent disturbance on a regulated river: A Missouri River case study. M.Sc. Thesis, University of South Dakota, USA.

[21] Adeloye, A.J., Wuni, I.Y., Dau, Q.V., Soundharajan, B.S. and Kasiviswanathan, K.S., 2019. Height-Area-Storage functional models for evaporation-loss inclusion in reservoir-planning analysis. Water, 11(7), p.1413.

[22] Oke, A.O., Ogedengbe, K. and Ajani, A.S., 2019. A Comparison of different methods for Bathymetric Survey and Sedimentation Evaluation of a Small Reservoir in Nigeria for Sustainable Management. Journal of Agriculture and Environment for International Development (JAEID), 113(2), pp.181-195.

[23] Adamo, N., Al-Ansari, N., Issa, I., Sissakian, V. and Knutsson, S., 2015. Mystery of Mosul Dam the most dangerous dam in the world: maintenance grouting. Journal of Earth Sciences and Geotechnical Engineering, 5(3), pp.71-77.

[24] Lawniczak-Malińska, A., Ptak, M., Celewicz, S. and Choiński, A., 2018. Impact of lake morphology and shallowing on the rate of overgrowth in hard-water eutrophic lakes. Water, 10(12), p.1827.

[25] Shang, S., 2013. Lake surface area method to define minimum ecological lake level from levelarea-storage curves. Journal of Arid Land, 5(2), pp.133-142.

[26] Albu, L.M., Enea, A., Iosub, M. and Breabăn, I.G., 2020. Dam Breach Size Comparison for Flood Simulations. A HEC-RAS Based, GIS Approach for Drăcșani Lake, Sitna River, Romania. Water, 12(4), p.1090.

[27] Al-Shahry, G.S.N. and Salih, S., 2017. Flood Routing of Tigris River in Baiji Station and Makhoul Dam Reservoir under Supposed Operation of the Dam. Tikrit Journal of Pure Science, 22(1), pp. 115-127. 